\title{
Outbreak of adenovirus type 1 severe pneumonia in a French intensive care unit, September-October 2012
}

N Cassir (cassirmadim@gmail.com)1,2,3, S Hraiech ${ }^{1,3,4}$, A Nougairede ${ }^{5,6}$, C Zandotti ${ }^{6}$, P E Fournier ${ }^{1,2}$, L Papazian $^{1,4}$

1. Unité de Recherche sur les Maladies Infectieuses Tropicales et Emergentes, UM63 CNRS 7278, IRD 189, Inserm U1095, IHU Méditerranée-Infection, Aix-Marseille Université, Marseille, France

2. Comité de Lutte contre les Infections Nosocomiales, Hôpital Nord, Assistance Publique-Hôpitaux de Marseille, Marseille, France

3. These authors contributed equally to the work

4. Service de Réanimation des Détresses Respiratoires et Infections Sévères, Hôpital Nord, Assistance Publique-Hôpitaux de Marseille, Marseille, France

5. Aix Marseille Université, IRD French Institute of Research for Development, EHESP French School of Public Health, EPV UMR_D 190 'Emergence des Pathologies Virales', 13385, Marseille, France

6. Laboratoire de Microbiologie Clinique, Hôpital de la Timone, Assistance Publique-Hôpitaux de Marseille, Marseille, France

Citation style for this article:

Cassir N, Hraiech S, Nougairede A, Zandotti C, Fournier PE, Papazian L. Outbreak of adenovirus type 1 severe pneumonia in a French intensive care unit, September-October 2012. Euro Surveill. 2014;19(39):pii=20914. Available online: http://www.eurosurveillance.org/ViewArticle.aspx?Articleld=20914

We herein describe and analyse the first outbreak of severe pneumonia caused by human adenovirus type 1 (HAdV C type 1), which included immunocompetent patients in an intensive care unit (ICU) of Marseille, France, and occurred between September and October 2012. Seven successive patients were diagnosed by HAdV specific real-time polymerase chain reaction with a positive bronchoalveolar lavage. After the collection of nasopharyngeal swabs from healthcare workers, three nurses working night shifts tested positive for HAdV C including one that had exhibited respiratory signs while working one week before the outbreak. She was the most likely source of the outbreak. Our findings suggest that HAdV-1 could be considered as a possible cause of severe pneumonia even in immunocompetent patients with a potential to cause outbreaks in ICUs. HAdV rapid identification and typing is needed to curtail the spread of this pathogen. Reinforcing hand hygiene with antiseptics with demonstrated activity against non-enveloped viruses and ensuring that HCWs with febrile respiratory symptoms avoid direct patient contact are critical measures to prevent transmission of HAdV in healthcare settings.

\section{Introduction}

Human adenoviruses (HAdVs) cause a broad spectrum of clinical presentations that range from asymptomatic to mild, severe and life-threatening infections. To date, more than 50 different types [1] of HAdVs have been identified, and they are grouped in seven different species $(A-G)$ on the basis of biochemical and molecular characteristics. Specific types have been linked to distinct clinical syndromes; HAdV-3, and HAdV-7 are common causes of severe pneumonia in neonates and children under five years of age [2]. HAdV-4 is among the most important causes of acute respiratory distress syndrome (ARDS) in new military recruits [3].
HAdV-11- and HAdV-14-associated febrile respiratory disease outbreaks have been reported in both children and adults $[4,5]$. Recently, HAdV-55 has been described as an emerging cause of community-acquired pneumonia in China [6]. Extra-pulmonary presentations have also been described and associated with specific types (i.e., infantile gastroenteritis: HAdV-40 and HAdV-41; epidemic keratoconjunctivitis: HAdV-8, HAdV-37 and HAdV-54; haemorrhagic cystitis: HAdV-11, HAdV-34 and HAdV-35) [7-9].

Transmission of HAdV may occur via aerosol droplets, by the faecal-oral route and by contact with contaminated fomites. In particular, adenoviruses may persist on human skin for many hours and survive for long periods on environmental surfaces [10]. One of their characteristics is their resistance to lipid disinfectants because they are non-enveloped. Thus, they are inactivated by high concentrations of alcohols (ethanol, isopropanol, $n$-propanol) or chlorine-based products. The virucidal activity of chlorhexidine is known to be low against adenoviruses [11]. Moreover, washing hands with soap and water has been described to be ineffective in eliminating adenovirus from the culturepositive hands of physicians and patients, indicating that mechanical removal was incomplete [12].

Outbreaks of HAdV pneumonia have been described in military and long-term care settings $[13,14]$. In a recent review about viral outbreaks in neonatal intensive care units (ICUs), HAdV outbreaks corresponded to $9.4 \%$ of all viral outbreaks and had the highest mortality rate, $35.4 \%$ [15].

We herein report an outbreak of HAdV C type 1 respiratory infections involving healthcare workers (HCWs) in a medical intensive care unit and describe the measures 
undertaken to control the outbreak and prevent new cases from occurring.

\section{Methods}

\section{Setting}

In September 2012, a HAdV-positive bronchoalveolar lavage (BAL) was identified from a patient hospitalised in the medical ICU in our university hospital. In the following outbreak, we defined our case-patients as patients hospitalised at the ICU with a HAdV-positive BAL associated with a clinical worsening of respiratory status or deterioration of their chest X-rays. The outbreak duration was defined as the time between the first and last case identification.

The 14-bed ICU serves critically ill adults with a particular recruitment of lung-transplanted patients, and patients with severe respiratory failure and infections. BALs from patients hospitalised in the ICU are routinely tested with a respiratory virus panel including influenza $A$ and $B$ viruses, human respiratory syncytial viruses $A$ and $B$, human rhinoviruses, human metapneumoviruses, human adenoviruses, human parainfluenzaviruses (1, 2, 3 and 4), and human coronaviruses (229 ${ }^{\mathrm{E}}, \mathrm{OC}_{43}$ and HKU1). All rooms are individually highefficiency particulate air (HEPA)-filtered.

\section{Laboratory Investigations}

Samples (BAL, nasopharyngeal swabs) for molecular detection of HAdV were analysed at the Virology Laboratory of the public hospitals of Marseille. Total nucleic acids extraction was performed using the EZ1-XL Biorobot with the Virus Mini Kit 2.0 (Qiagen, Hilden, Germany) from $200 \mu$ l of BAL. Quantitative molecular detection of HAdV was performed using the commercial Adenovirus R-gene kit (Argene, BioMerieux, Marcy l'Etoile, France) according to the manufacturer's instructions.

The HAdV species detected (A, B, C, D, E, F or G) was determined using six real-time polymerase chain reaction (PCR) assays as previously described [16]: briefly, $10 \mu \mathrm{l}$ of total nucleic acids extract was used to perform a real-time PCR using a $\mathrm{C}_{1000 T o u c h / C F X 96}$ thermocycler (Bio-Rad, Marnes-la-Coquette, France), the Fast qPCRMastermix - No ROX kit (Eurogentec, Angers, France) and a standard cycling protocol recommended by the manufacturer.

The type of the HAdV C was determined by sequencing the hexon hypervariable region as described previously [17]: in short, $5 \mu$ l of total nucleic acids extract was used to perform a PCR using the Platinum PCR SuperMix High Fidelity kit (Life Technologies, SaintAubin, France), the primers AdV_HVR_PCR_C_F1 (5'-ATGATGCCGCAGTGGTCTTAC-3'), and AdV_HVR PCR_C_R1 (5'-ATTAAAGGACTGGTCGTTGGTGTC-3') and a standard cycling protocol (annealing temperature: $58^{\circ} \mathrm{C}$ ). Amplicons were sequenced using the following previously described primers (AdV_HVR_PCR_C_F2:
5'-ACG ACG TRA CCA CAG ACC G-3'; AdV_HVR_PCR_C_ R2: 5'-GCC ACC ACT CGC TTG TTC AT-3'; AdV_HVR_ Seq_CF652: 5'-GGM GAA TCT CAG TGG WAY GAA-3'; AdV_HVR_Seq_F1183: 5'-TAY TTT TCY ATG TGG AAK CAG GC-3'; AdV_HVR_Seq_R1148: 5'-TGR TAK GAM AGC TCT GTG TTT CTG-3'; AdV_HVR_Seq_R744: 5'-ATA NGA WCC RTA RCA TGG TTT (AT-3'). Data from sequencing reactions were combined for analysis and edited using the Sequencer 5.1 software (Gene Codes Corporation, Ann Arbor, USA). All types found using this method were HAdV type 1 (results were subjected to BLAST analysis [18]. We used Clustal $X$ [19] to align these sequences with other homologous sequences of HAdV C (HAdV-1 : AC_000017, AF534906, Fl943633, Fl943635, FJ943621, and DQ336392; HAdV-2 : AC_000007 and J01917; HAdV-5: AC_000008 and AY601635; HAdV-6: HQ413315). Based on this alignment of the hexon hypervariable region, two primers (forward: 5'-ATGCTCAGGCTCCTTTGGCAGG-3'; reverse: 5'-TCAGCTTCATTCCACTGAGATTCT CC-3'; PCR-product length: $148 \mathrm{bp}$ ) were designed for a region with high inter- type variability to specifically detect the HAdV-1, and a SYBR Green real-time PCR assay was performed with $10 \mu$ l of total nucleic acids extract, the Quantitec SYBR Green PCR kit (Qiagen), a C100oTouch/CFX96 thermocycler (Bio-Rad) and a standard protocol (annealing temperature: $60^{\circ} \mathrm{C}$ ) with a melting-curve analysis. The specificity of the assay was assessed with two samples positive for HAdV-2 and three samples positive for HAdV-B: all were negative (data not shown).

\section{Infection Control Measures}

The infection control team was alerted after confirmation of the first case-patient. The initial intervention in the ICU consisted of placing the patients who tested positive for HAdV under contact and droplet precautions as recommended by the French Society of Hospital Hygiene [20], and limiting visits from their relatives. Other infection control measures that were implemented included the recommended use of alcohol-based hand rub with a product (Hanlabs bloc'K, Christeyns, Vertou, France) evaluated for its effectiveness against non-enveloped viruses according to the European Norm (EN) 14476. Reinforcement of hand hygiene consisted in daily information and surveillance of hand hygiene compliance. Daily environmental surfaces disinfection with a prepared sodium hypochlorite aqueous solution was implemented. Qualitative assessment of the compliance with these measures was carried out by the presence of an infection control team member supervising practices once daily until the end of the outbreak. All HCWs were reminded that if they had respiratory signs or a fever that they should avoid coming to work or when working wear a surgical mask at all times until being asymptomatic.

In addition, nasopharyngeal swabs were collected from HCWs working at the ICU. Among all $101 \mathrm{HCWs}(13$ physicians and 88 nurses), 43\% (13 physicians and 30 nurses) voluntarily accepted to be sampled for HAdV testing. An information sheet about HAdV transmission 
that included measures to prevent secondary cases in household contacts was given to all HCWs and to the relatives of the patients.

\section{Results}

\section{Outbreak description}

The first case-patient of the HAdV outbreak was identified on 15 September and the last one 19 days later, on 4 October 2012 (Figure). During the outbreak period, seven ( 5 men, 2 women) of 30 patients admitted to the ICU had a positive BAL for HAdV. We assumed that six of the seven infections were nosocomially-acquired because the time from hospital admission to an HAdVpositive sample was greater than the incubation period for HAdV (range 2-14 days) or prior BAL samples had been negative [21].

Of the seven patients, three had recently received lung transplants; the remaining four had been admitted to the ICU for acute respiratory failure. One patient suffered from lung cancer. The average age was 48.5 years old (range 31-67). The time from admission to the ICU to positive BAL ranged from one to 51 days. All positive patients were mechanically ventilated at the time of the sampling. Lung-transplanted patients were treated with methylprednisolone and tacrolimus (Table 1). Clinical worsening of respiratory status at the time of the generation of the positive sample was observed in six of the patients, whereas one patient was asymptomatic and HAdV was diagnosed in a routine control BAL. However, for this patient we observed a deterioration of their chest radiography with the increase in interstitial diffuse opacities. Of the six patients who had a clinical degradation, four had a BAL also positive for bacteria, suggesting a co-infection. For further two patients, HAdV was the only pathogen identified in their BAL. Three patients died at the ICU. Death occurred six days after the positive sample for one patient and 20 and 23 days after the symptom onset for the other two respectively.

The HAdV species was determined for six of seven patients, and the result was $C$ for all of them. We identified HAdV-1 in the BAL of five patients by real-time PCR (Table 2). Furthermore, all sequences of the hexon hypervariable region were $100 \%$ identical (GenBank accession number: KM610306), suggesting a common source of infection. The HAdV type was not identified for two patients because of a very low quantity of HAdV DNA detected using our quantitative assay (data not shown). No other patients positive for HAdV $C$ were identified during the outbreak in the hospital. Case-patients were distributed all-over the ICU. It was confirmed that the three positive nurses took care of all those patients. Only two bronchoscopes were used during the outbreak period, and those who performed the procedure were identified for each BAL performed. There was neither bronchoscope- nor user-associated HAdV PCR positivity (data not shown).

\section{FIGURE}

Timeline of diagnosis and outcomes for patients with human adenovirus type 1 severe pneumonia during their stay in the intensive care unit, human adenovirus type 1 outbreak, Marseille, France, September-October $2012(\mathrm{n}=7)$
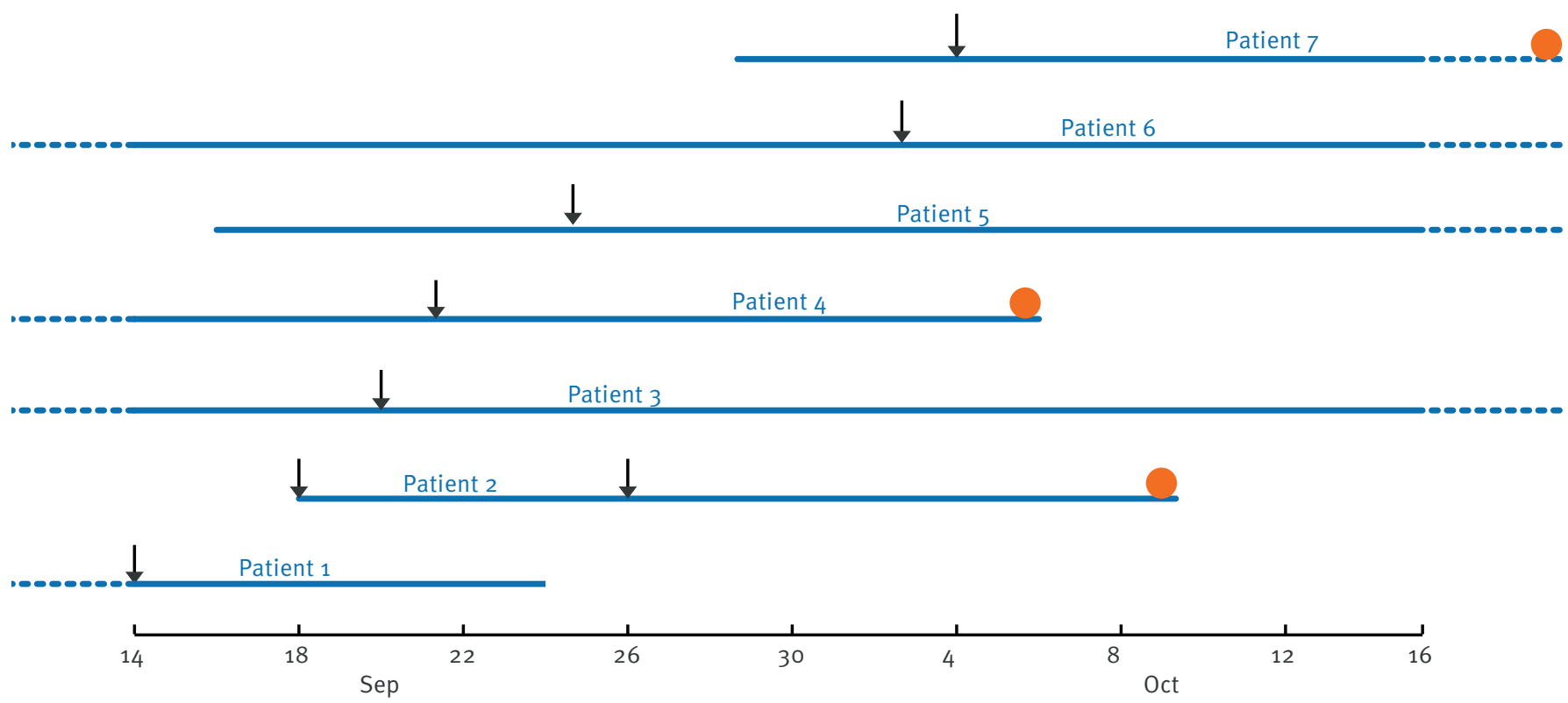


\section{TABLE 1}

Characteristics and clinical outcomes of patients with human adenovirus type 1 severe pneumonia, human adenovirus type 1 outbreak, Marseille, France, September-October 2012 ( $n=7)$

\begin{tabular}{|c|c|c|c|c|c|c|c|c|}
\hline $\begin{array}{l}\text { Chronological } \\
\text { order of } \\
\text { positive BAL }\end{array}$ & $\begin{array}{c}\text { Age } \\
\text { (years) }\end{array}$ & Sex & $\begin{array}{l}\text { Time from } \\
\text { admission } \\
\text { to BAL } \\
\text { positivity } \\
\text { (days) }\end{array}$ & $\begin{array}{l}\text { Diagnosis at } \\
\text { admission }\end{array}$ & $\begin{array}{l}\text { Diagnosis at the } \\
\text { time of } B A L\end{array}$ & $\begin{array}{c}\text { Associated } \\
\text { bacteriological } \\
\text { infection } \\
\text { documented in } \\
\text { BAL }\end{array}$ & $\begin{array}{l}\text { Chest X-ray } \\
\text { or computed } \\
\text { tomography }\end{array}$ & $\begin{array}{l}\text { Outcome at } \\
\text { discharge }\end{array}$ \\
\hline 1 & 53 & $M$ & 26 & Lung transplantation & $\begin{array}{c}\text { Severe } \\
\text { pneumonia }\end{array}$ & None & $\begin{array}{l}\text { Increase } \\
\text { of bilateral } \\
\text { alveolar } \\
\text { opacities }\end{array}$ & Alive \\
\hline 2 & 49 & $\mathrm{~F}$ & 1 & $\begin{array}{c}\text { Aspiration } \\
\text { pneumonia/ARDS }\end{array}$ & $\begin{array}{c}\text { Severe ARDS } \\
\text { and septic shock }\end{array}$ & None & $\begin{array}{l}\text { Bilateral } \\
\text { diffused } \\
\text { opacities }\end{array}$ & Death \\
\hline 3 & 52 & M & 51 & $\begin{array}{l}\text { Right lobectomy for } \\
\text { lung abscess }\end{array}$ & $\begin{array}{c}\text { Severe } \\
\text { pneumonia }\end{array}$ & $\begin{array}{c}\text { Pseudomonas } \\
\text { aeruginosa }\end{array}$ & $\begin{array}{c}\text { Right } \\
\text { alveolar } \\
\text { opacities }\end{array}$ & Alive \\
\hline 4 & 67 & M & 49 & $\begin{array}{l}\text { Nosocomial } \\
\text { pneumonia }\end{array}$ & $\begin{array}{c}\text { Ventilator } \\
\text { weaning failure }\end{array}$ & MRSA & $\begin{array}{l}\text { Increase of } \\
\text { basal left } \\
\text { alveolar } \\
\text { opacities }\end{array}$ & Death \\
\hline 5 & 45 & $\mathrm{~F}$ & 10 & Lung transplantation & ARDS & MRSA & $\begin{array}{l}\text { Bilateral } \\
\text { diffused } \\
\text { opacities }\end{array}$ & Alive \\
\hline 6 & 31 & M & 26 & $\begin{array}{l}\text { Septic shock } \\
\text { mediastinitis }\end{array}$ & $\begin{array}{c}\text { Severe } \\
\text { pneumonia }\end{array}$ & $\begin{array}{c}\text { Enterobacter } \\
\text { cloacae }\end{array}$ & $\begin{array}{l}\text { Left lung } \\
\text { alveolar } \\
\text { opacities }\end{array}$ & Alive \\
\hline 7 & 43 & M & 3 & Lung transplantation & $\begin{array}{l}\text { Asymptomatic, } \\
\text { routine } B A L\end{array}$ & None & $\begin{array}{l}\text { Increase of } \\
\text { right lung } \\
\text { alveolar } \\
\text { opacities }\end{array}$ & Death \\
\hline
\end{tabular}

ARDS: acute respiratory distress syndrome; BAL: bronchoalveolar lavage; F: females; M:males; MRSA: meticillin-resistant Staphylococcus aureus.

\section{TABLE 2}

Laboratory results for infected patients $(n=7)$ and healthcare workers $(n=3)$ in the intensive care unit, human adenovirus type 1 outbreak, Marseille, France, September-October 2012

\begin{tabular}{|c|c|c|c|c|c|}
\hline & & Sample & $\begin{array}{l}\text { Specific HAdV } \\
\text { q-real-time PCR }\end{array}$ & Species & HAdV type \\
\hline \multirow{7}{*}{ Patients } & 1 & BAL & Positive & C & 1 \\
\hline & 2 & BAL & Positive & C & 1 \\
\hline & 3 & BAL & Positive & $\mathrm{C}$ & n.a. \\
\hline & 4 & BAL & Positive & $\mathrm{C}$ & 1 \\
\hline & 5 & BAL & Positive & $\mathrm{C}$ & 1 \\
\hline & 6 & BAL & Positive & $\mathrm{C}$ & 1 \\
\hline & 7 & BAL & Positive & n.a. & n.a. \\
\hline \multirow{3}{*}{ HCWs } & 1 & Nasopharyngeal swab & Positive & C & n.a. \\
\hline & 2 & Nasopharyngeal swab & Positive & n.a. & n.a. \\
\hline & 3 & Nasopharyngeal swab & Positive & n.a. & n.a. \\
\hline
\end{tabular}

HCWs: healthcare workers; BAL: bronchoalveolar lavage; HAdV: human adenovirus ; PCR: polymerase chain reaction; n.a.: not available. 
Testing of healthcare workers

Nasopharyngeal swabs were collected from $43 \mathrm{HCWs}$ (all asymptomatic when sampled) and three tested positive for HAdV. They were all nurses working night shifts at the time of the outbreak. Interestingly, for one of them (nurse 1 in Table 2), identification to the species level was possible, and a $\mathrm{C}$ species was identified. Moreover, after systematic interviews with all HCWs who had had contact with the first identified casepatient within two weeks before the outbreak started, it appeared that nurse 1 was the only one who reported having fever with mild respiratory symptoms one week before. Upper or lower respiratory tract infection could not be determined in the absence of chest X-ray. She came to work without wearing a surgical mask.

None of the HCWs reported having relatives with fever or respiratory signs during the outbreak period.

\section{Effectiveness of Infection Control Measures} Infection control measures were initiated on the day after the first acute patient had had onset of respiratory failure, when the virological results were received. of the six case-patients who emerged after implementing control measures, five had either been subsequently infected or already been in incubation. We could not include patient two as a case-contact in this outbreak because she was positive for HAdV already at admission, suggesting an acquisition outside our hospital. Neither HCWs nor relatives developed symptoms after the first onset in patients. Surveillance showed better hand hygiene compliance over time.

No other HAdV-positive patient was diagnosed at the ICU during the 12 months of follow-up.

\section{Discussion}

We here described an outbreak of severe pneumonia caused by HAdV in a French ICU.

Recent studies have raised concerns about viral infections as a common cause of community-acquired and nosocomial pneumonia $[22,23]$. Availability of efficient molecular diagnostic tests and increased immunosuppressed population may have contributed to this trend. In a recent South African study using a multiplex realtime PCR for the identification of common viruses in patients hospitalised with severe acute respiratory illness, $13 \%$ were positive for HAdV [24]. In another study, the prevalence of HAdV was $3.8 \%$ among SubSaharan African children with severe pneumonia [25].

Our second patient was diagnosed one day after admission. She had been transferred from a peripheral hospital in the northwest of Marseille, suggesting a regional circulation of the virus. At the time of the outbreak, no other cases of HAdVs were reported in Marseille public hospitals (data not shown). Nevertheless, HAdV typing is not commonly performed for respiratory samples and thus, community-wide outbreaks of adenovirus are not easily detected. Previous reports are limited to those occurring in hospital, school, or military settings $[3,26,27]$. Rapid HAdV identification and typing is needed to curtail the spread of this pathogen, as shown in a recent investigation of the transmission of HAdV-14 from infected hospitalised patients to HCWs [14].

Virus detection does not necessarily mean clinically manifest disease [28]. However, in a recent populationbased study, it was shown that when a viral infection is present either alone or during the same hospitalisation together with a bacterial infection, it is associated with an increased risk of mortality, ARDS, multi-system organ failure and septic shock. Interestingly, coinfections showed the strongest association with each adverse outcome [29]. In our study, bacterial co-infections were found in four of the seven patients. Severe immunosuppression remains a leading risk factor for disseminated HAdV disease and is associated with high mortality [30]. In particular, HAdV-1, HAdV-2 and HAdV-5, belonging to species HAdV C, were described as being frequently associated with disseminated disease in highly immunosuppressed patients $[30,31]$. In our study, there were three lung-transplanted patients and three immunocompetent patients; three patients died (1 lung-transplanted, 2 immunocompetent), and three improved without specific treatment for HAdV or modification of their immunosuppressive therapy. The relatively small number of patients precludes any comparative study with controls. Nonetheless, the HAdV PCR positivity in the BAL suggests a replication in the lungs that favours the hypothesis of an active infection.

As part of the measures implemented to prevent onward transmission in our hospital, we recommended a reinforcement of hand hygiene. Particularly, the substitution of the previous alcohol-based hand rub with a product evaluated for its effectiveness against nonenveloped viruses seemed critical for the control of the outbreak. In fact, the virucidal activity of the previously used alcohol-based hand rub was not tested, and it is not mandatory for a product to be listed as effective for hygienic hand disinfection by the French Society for Hospital Hygiene [32]. However, as previously observed, replacement of hand and surface disinfectant with a product proven to be active against nonenveloped viruses is essential in order to interrupt the chain of transmission during adenoviral infection outbreaks [33]. The second critical measure implemented to control our outbreak was to remind all HCWs that if they had respiratory signs or a fever that they should avoid coming to work or when working wear a surgical mask at all times until free of signs and symptoms.

We reported here, to the best of our knowledge, the first HAdV-1 pneumonia outbreak in mechanical ventilated critically ill patients involving immunocompetent patients. In this particular population, cross-transmission can occur during aerosol-generating procedures (i.e., bronchoscopy, nasotracheal suctioning) or by endotracheal tube contamination from hands during medication. The nurse who worked while exhibiting 
respiratory signs and symptoms without wearing a mask might have been the source of the outbreak herein reported, but the route of transmission and a causal link could not be determined. Moreover, the fact that less than half of HCWs were tested for HAdV most likely results in an underestimation of viral circulation among this population during the outbreak.

\section{Conclusion}

Our findings suggest that HAdV C type 1 could be considered as a possible cause of severe pneumonia even in immunocompetent patients with a potential to cause outbreaks in ICUs. HAdV rapid identification and typing is needed to curtail the spread of this pathogen. Reinforcing hand hygiene with antiseptics with demonstrated activity against non-enveloped viruses and ensuring that HCWs with febrile respiratory symptoms avoid direct patient contact are critical measures to prevent transmission of HAdV in healthcare settings.

\section{Acknowledgements}

We acknowledge Georgette Grech for her technical assistance.

\section{Conflict of interest}

None declared.

\section{Authors' contributions}

NC wrote the manuscript, performed the outbreak investigation, analysed and interpreted the patient data. SH was a major contributor in writing the manuscript and took care of the patients. AN wrote the manuscript and performed the microbiological investigations. CZ helped perform the microbiological investigation. PEF wrote the manuscript. LP took care of the patients and wrote the manuscript. All authors read and approved the final manuscript.

\section{References}

1. Walsh MP Seto J, Jones MS, Chodosh J, Xu W, Seto D. Computational analysis identifies human adenovirus type 55 as a re-emergent acute respiratory disease pathogen. Clin Microbiol. 2010;48(3):991-3. http://dx.doi.org/10.1128/ JCM.01694-09

2. Carballal G, Videla C, Misirlian A, Requeijo PV, Aguilar M del C. Adenovirus type 7 associated with severe and fatal acute lower respiratory infections in Argentine children. BMC Pediatr. 2002;2:6. http://dx.doi.org/10.1186/1471-2431-2-6

3. Kolavic-Gray SA, Binn LN, Sanchez JL, Cersovsky SB, Polyak CS, Mitchell-Raymundo F, et al. Large epidemic of adenovirus type 4 infection among military trainees: epidemiological, clinical, and laboratory studies. Clin Infect Dis. 2002;35(7):808-18. http://dx.doi.org/10.1086/342573

4. Kajon AE, Dickson LM, Metzgar D, Houng H-S, Lee V, Tan $\mathrm{B}-\mathrm{H}$. Outbreak of febrile respiratory illness associated with adenovirus 11a infection in a Singapore military training CAMP. I Clin Microbiol. 2010;48(4):1438-41. http://dx.doi.org/10.1128/ JCM.01928-09

5. Trei JS, Johns NM, Garner JL, Noel LB, Ortman BV, Ensz KL, et al. Spread of adenovirus to geographically dispersed military installations, May-October 2007. Emerg Infect Dis. 2010;16(5):769-75. http://dx.doi.org/10.3201/eid1605.091633

6. Cao B, Huang G-H, Pu Z-H, Qu J-X, Yu X-M, Zhu Z, et al. Emergence of community-acquired adenovirus type 55 as a cause of community-onset pneumonia. Chest. 2014;145(1):79 86. http://dx.doi.org/10.1378/chest.13-1186
7. Filho EP, da Costa Faria NR, Fialho AM, de Assis RS, Almeida MMS, Rocha M, et al. Adenoviruses associated with acute gastroenteritis in hospitalized and community children up to 5 years old in Rio de Janeiro and Salvador, Brazil. J Med Microbiol. 2007;56(Pt 3):313-9. http://dx.doi.org/10.1099/ jmm.0.46685-0

8. Kaneko H, Suzutani T, Aoki K, Kitaichi N, Ishida S, Ishiko H, et al. Epidemiological and virological features of epidemic keratoconjunctivitis due to new human adenovirus type 54 in Japan. Br J Ophthalmol. 2011;95(1):32-6. http://dx.doi. org/10.1136/bjo.2009.178772

9. Hofland CA, Eron LJ, Washecka RM. Hemorrhagic adenovirus cystitis after renal transplantation. Transplant Proc. 2004;36(10):3025-7. http://dx.doi.org/10.1016/j. transproceed.2004.10.090

10. Sattar SA, Springthorpe VS, Tetro J, Vashon R, Keswick B. Hygienic hand antiseptics: should they not have activity and label claims against viruses? Am J Infect Control. 2002;30(6):355-72. http://dx.doi.org/10.1067/mic.2002.124532

11. Kampf G, Kramer A. Epidemiologic background of hand hygiene and evaluation of the most important agents for scrubs and rubs. Clin Microbiol Rev. 2004;17(4):863-93. http://dx.doi. org/10.1128/CMR.17.4.863-893.2004

12. Jernigan JA, Lowry BS, Hayden FG, Kyger SA, Conway BP, Gröschel DH, et al. Adenovirus type 8 epidemic keratoconjunctivitis in an eye clinic: risk factors and control. J Infect Dis. 1993;167(6):1307-13. http://dx.doi.org/10.1093/ infdis/167.6.1307

13. Klinger JR, Sanchez MP, Curtin LA, Durkin M, Matyas B. Multiple cases of life-threatening adenovirus pneumonia in a mental health care center. Am J Respir Crit Care Med. 1998;157(2):645-9. http://dx.doi.org/10.1164/ ajrccm.157.2.9608057

14. Lessa FC, Gould PL, Pascoe N, Erdman DD, Lu X, Bunning ML, et al. Health care transmission of a newly emergent adenovirus serotype in health care personnel at a military hospital in Texas, 2007. J Infect Dis. 2009;200(11):1759-65. http://dx.doi. org/10.1086/647987

15. Civardi E, Tzialla C, Baldanti F, Strocchio L, Manzoni P, Stronati $M$. Viral outbreaks in neonatal intensive care units: What we do not know. Am J Infect Control. 2013;41(10):854-6. http://dx.doi. org/10.1016/j.ajic.2013.01.026

16. Watzinger F, Suda M, Preuner S, Baumgartinger R, Ebner K, Baskova L, et al. Real-time quantitative PCR assays for detection and monitoring of pathogenic human viruses in immunosuppressed pediatric patients. J Clin Microbiol. 2004;42(11):5189-98. http://dx.doi.org/10.1128/ JCM.42.11.5189-5198.2004

17. Biere $B$, Schweiger $B$. Human adenoviruses in respiratory infections: sequencing of the hexon hypervariable region reveals high sequence variability. J Clin Virol. 2010;47(4):36671. http://dx.doi.org/10.1016/j.jcv.2010.01.005

18. Altschul SF, Gish W, Miller W, Myers EW, Lipman DJ. Basic local alignment search tool. J Mol Biol. 1990;215(3):403-10. http:// dx.doi.org/10.1016/So022-2836(05)80360-2

19. Larkin MA, Blackshields G, Brown NP, Chenna R, McGettigan PA, McWilliam H, et al. Clustal $W$ and Clustal $X$ version 2.0. Bioinformatics. 2007;23(21):2947-8. http://dx.doi.org/10.1093/ bioinformatics/btm 404

20. Société francaise d'hygiène hospitalière: prévention de la transmission croisée par voie respiratoire : air ou gouttelettes. Hygiènes. 2013;21(1):1-40.

21. Lynch JP, Fishbein M, Echavarria M. Adenovirus. Semin Respir Crit Care Med. 2011;32(4):494-511. http://dx.doi. org/10.1055/s-0031-1283287

22. Johnstone J, Majumdar SR, Fox JD, Marrie TJ. Viral infection in adults hospitalized with community-acquired pneumonia: prevalence, pathogens, and presentation. Chest. 2008;134(6):1141-8. http://dx.doi.org/10.1378/chest.08-0888

23. Chiche L, Forel J-M, Papazian L. The role of viruses in nosocomial pneumonia. Curr Opin Infect Dis. 2011;24(2):152-6. http://dx.doi.org/10.1097/QCO.obo13e328343b6e4

24. Pretorius MA, Madhi SA, Cohen C, Naidoo D, Groome M, Moyes J, et al. Respiratory viral coinfections identified by a 10 -plex real-time reverse-transcription polymerase chain reaction assay in patients hospitalized with severe acute respiratory illness--South Africa, 2009-2010. J Infect Dis. 2012;206(Suppl 1):S159-65. http://dx.doi.org/10.1093/infdis/jis538

25. Berkley JA, Munywoki P, Ngama M, Kazungu S, Abwao J, Bett $A$, et al. Viral etiology of severe pneumonia among Kenyan infants and children. JAMA. 2010;303(20):2051-7. http://dx.doi. org/10.1001/jama.2010.675

26. Hong JY, Lee HJ, Piedra PA, Choi EH, Park KH, Koh YY, et al. Lower respiratory tract infections due to adenovirus in hospitalized Korean children: epidemiology, clinical features, 
and prognosis. Clin Infect Dis. 2001;32(10):1423-9. http:// dx.doi.org/10.1086/320146

27. Xie L, Yu X-F, Sun Z, Yang X-H, Huang R-J, Wang J, et al. Two adenovirus serotype 3 outbreaks associated with febrile respiratory disease and pharyngoconjunctival fever in children under 15 years of age in Hangzhou, China, during 2011. J Clin Microbiol. 2012;50(6):1879-88. http://dx.doi.org/10.1128/ JCM.06523-11

28. Luyt C-E. Virus diseases in ICU patients: a long time underestimated; but be aware of overestimation. Intensive Care Med. 2006;32(7):968-70. http://dx.doi.org/10.1007/ S00134-006-0203-9

29. Miggins M, Hasan A, Hohmann S, Southwick F, Casella G, Schain D, et al. The potential influence of common viral infections diagnosed during hospitalization among critically ill patients in the United States. PLoS ONE. 2011;6(4):e18890. http://dx.doi.org/10.1371/journal.pone.0018890

30. Echavarría M. Adenoviruses in immunocompromised hosts. Clin Microbiol Rev. 2008;21(4):704-15. http://dx.doi. org/10.1128/CMR.00052-07

31. Ganzenmueller T, Buchholz S, Harste G, Dammann E, Trenschel $R$, Heim A. High lethality of human adenovirus disease in adult allogeneic stem cell transplant recipients with high adenoviral blood load. J Clin Virol. 2011;52(1):55-9. http://dx.doi. org/10.1016/j.jcv.2011.06.005

32. Société francaise d'hygiène hospitalière: Liste positive désinfectants. Hygiènes. 2009;17(3):1-24.

33. Chaberny IE, Schnitzler P, Geiss HK, Wendt C. An outbreak of epidemic keratoconjunctivtis in a pediatric unit due to adenovirus type 8. Infect Control Hosp Epidemiol. 2003;24(7):514-9. http://dx.doi.org/10.1086/502247 